\title{
A Case of Anesthetic Treatment of Appendicectomy to a Patient under Potato Poisoning
}

\author{
Xi Yang1, Jun Li² \\ ${ }^{1}$ Department of Anesthesiology, Sichuan Academy of Medical Sciences \& Sichuan Provincial People's Hospital, \\ Chengdu, China \\ ${ }^{2}$ Departmen of Anesthesiology, Chengdu Military General Hospital, Chengdu, China \\ Email: 552309660@qq.com
}

Received 4 February 2015; accepted 17 April 2015; published 22 April 2015

Copyright @ 2015 by authors and Scientific Research Publishing Inc.

This work is licensed under the Creative Commons Attribution International License (CC BY).

http://creativecommons.org/licenses/by/4.0/

(c) (1) Open Access

\section{Abstract}

We reported a case of anesthetic treatment of appendicectomy to a patient under potato poisoning. The overview of potato poisoning has been reviewed in the report and the symptom of the patient under potato poisoning comparing with other appendicitis patients has been described. We highlighted the deference of methodology of anesthetic treatment comparing the patient under potato poisoning with other appendicitis patients.

\section{Keywords}

\section{Potato Poisoning, Appendicectomy, Anesthetic Treatment}

\section{Introduction}

Potato poisoning occurs after consumption of green potato, particularly parts of the plant richer in alkaloid such as sprouts or peel. It has reported that unripe or sprouting potato tubers contain toxins alkaloid including solanine, chaconine, trypsin, chymotrypsin and cell lectin, among which solanine and chaconine have a synergistic toxic effect, and the toxicity reaches the maximum when the ratio between both is 1:1 [1]. Solanine is the toxin playing a leading role among these chemicals. It is an alkalescent glycoside alkaloids. There were many clinical case reports of potato poisoning before 80's in the last century around the world. Potato poisoning is well recognized. Neurological effects are prominent and include apathy, drowsiness, trembling, dyspnoea, weakness or paralysis, unconsciousness. The pupils are sometimes dilated. Gastrointestinal symptoms vary from minor to very severe haemorrhagic ulceration of the mucosae. A few documents describe the pathophysiology, clinical 
manifestations, diagnosis, treatment and complications of such rare diseases as potato poisoning. Meanwhile, Potato poisoning is uncommon in recent years. Researches focus on the systemic effects of solanine in vivo and in vitro [2] [3]. There was not any reports described the course of surgery or methodology of anesthetic treatment during operation to a patient under potato poisoning. Here we report a case of anesthetic treatment of appendicectomy to a patient who undergoing potato poisoning.

\section{Case Report}

The patient was male, 16-year-old and $48 \mathrm{~kg}$. 9 days before being hospitalized, he had eaten leftovers of lunch the very same day (potatoes based), sweet soupballs, and grapes. On the next morning when he got up, he experienced manifestations of dizziness, vertigo and vomit, the character and frequency of vomit being unknown. Without manifestations of diarrhea, convulsions or else, he was sent to the local hospital for treatment. How he was exactly treated remains unknown, and his illness has not bettered. 4 days before being hospitalized, the patient had experienced poor spontaneous respiration and was unable to respond to calls. After being treated with tracheal cannula, respirator-assisted respiration, dehydration, anti-infection, acid inhibition, dilation, etc, the patient's consciousness turned sober, but he remained reliant on mechanical ventilation. For further salvage and therapy, the patient was accepted in our hospital, diagnosed as acute potato poisoning combined with acute appendicitis after being hospitalized (Figure 1).

The patient was applied with comprehensive emergency treatments, such as fasting, mechanical ventilation, rehydration, diuretic, detoxification, etc. His Physical examination results at this time are shown in Table 1 . His laboratory test results are shown in Table 2. A chest radiograph indicated heart and lungs were normal, ECG indicating sinus rhythm of V3 T wave inversion in leads.

We have planned to carry out an appendicectomy on the patient under general anesthesia. Since the tracheal cannula has been implemented on him, the mechanical ventilation is implemented straightforward with VT 350 ml, Rf 12 BPM, IE 1:2, oxygen flow rate $3 \mathrm{~L} / \mathrm{min}, \mathrm{FiO}_{2} 100 \%$. Induction of anesthesia was performed using a bolus of $50 \mathrm{mg}$ propofol, without significant changes in vital signs. Blood pressure was at 100/60 mmHg and heart rate at 78 beats/min. When the surgery began we applied a continuous infusion of $40 \mathrm{ml} / \mathrm{h}$ propofol, a continuous infusion of $0.14 \mathrm{ug} /(\mathrm{kg} \cdot \mathrm{min})$ remifentanil, and inhalation of 3\% Sevoflurane. As blood pressure dropped to $110 / 70 \mathrm{mmHg}$ and heart rate to 90 beats/min, we replaced with propofol $20 \mathrm{ml} / \mathrm{h}$, remifentanil $0.07 \mathrm{ug} /(\mathrm{kg} \cdot \mathrm{min})$, and $1 \%$ sevoflurane, maintaining it until the surgery ended, throughout which the vital signs were stable. Within the drug discontinuance of 5 min after the surgery, the patients became sober with heart rate at 90 beats/min, blood pressure at 110/70 mmHg, and oxygen saturation at 99\%. In the follow-up visit three days later, the patient was sober, his muscular tension being on level 3, and he was able to waver his fingers to give a sign. But he still needed the respirator to assist with respiration. Since then, the patient was transferred to another hospital.

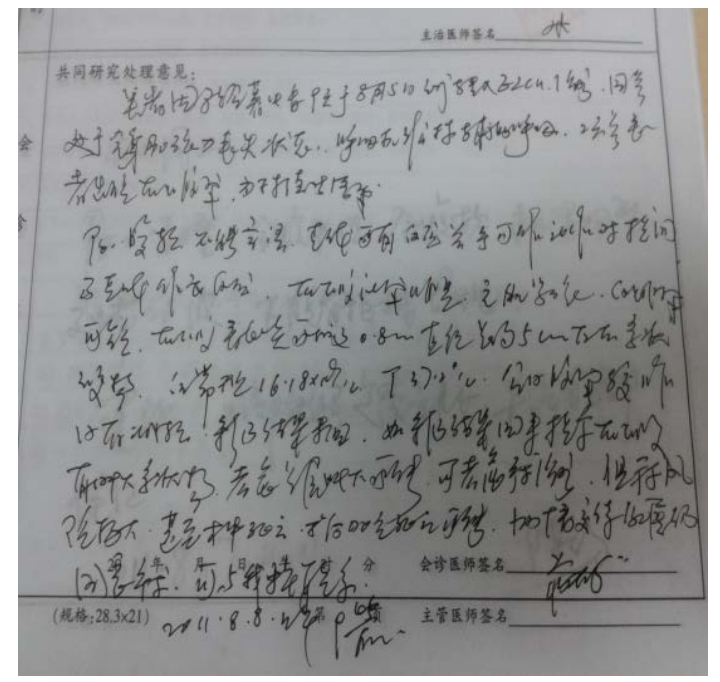

Figure 1. The consultation record in emergency department showing the diagnosis of appendicitis with complication of potato poisoning. 
Table 1. Results of physical examination.

\begin{tabular}{|c|c|c|c|c|}
\hline Basic vital signs & HP: 98 bpm & $\begin{array}{c}\text { BP: } 122 / 80 \\
\text { MmHg }\end{array}$ & $\begin{array}{l}\text { RR: } 12 \text { bpm } \\
\text { (respirator-assisted } \\
\text { respiration) }\end{array}$ & $\begin{array}{c}\text { SPO2: } \\
90 \%\end{array}$ \\
\hline Pupil bilateral (mm) & \multicolumn{4}{|c|}{4.5} \\
\hline Light reflex & \multicolumn{4}{|c|}{ delays } \\
\hline Double lung auscultation & \multicolumn{4}{|c|}{ clear } \\
\hline $\begin{array}{l}\text { Consciousness } \\
\text { Manual Muscle Test } \\
\text { (a standardized clinical } \\
\text { examination used to measure } \\
\text { strength of l muscle groups) }\end{array}$ & \multicolumn{4}{|c|}{$\begin{array}{l}\text { somnolence } \\
\text { poor }\end{array}$} \\
\hline
\end{tabular}

Table 2. Results of laboratory tests.

\begin{tabular}{ccc}
\hline & Results & Reference \\
\hline Urea $(\mathrm{mmol} / \mathrm{L})$ & 10.08 & $3.2-7.4$ \\
$\mathrm{P}(\mathrm{mmol} / \mathrm{L})$ & 1.69 & $0.81-1.45$ \\
Albumin/globulin blobulin & 1.12 & $1.2-2.5$ \\
Aspartate/alanine & 0.76 & $1.2-2.5$ \\
$\mathrm{PH}$ & 7.42 & $7.35-7.45$ \\
$\mathrm{PO}_{2}(\mathrm{kPa})$ & 30 & $7.35-7.45$ \\
$\mathrm{TCO}_{2}(\%)$ & 25.1 & $24-32$ \\
$\mathrm{Na}^{+}(\mathrm{mmol} / \mathrm{L})$ & 133 & $135-145$ \\
$\mathrm{~K}(\mathrm{mmol} / \mathrm{L})$ & 3.3 & $3.3-5.5$ \\
$\mathrm{Ca}(\mathrm{mmol} / \mathrm{L})$ & 1.10 & $1.13-1.35$ \\
$\mathrm{Hbg} / \mathrm{L}$ & 124 & $110-160$ \\
$\mathrm{Hct}(\%)$ & 40 & $37-49$ \\
\hline
\end{tabular}

\section{Discussion}

When solanine is consumed at $0.4-0.6 \mathrm{mg} / \mathrm{kg}$, the symptoms of nausea and emesis may occur, and the lethal dose is $3-6 \mathrm{mg} / \mathrm{kg}$ [4]. Solanine is strongly offensive and corrosive to gastrointestinal mucosa [5], and has a paralytic effect on central nervous system, which is especially significant on respiratory and motorcenters [6] [7]. Besides, it has dissolution on red blood cells and can cause hemolysis [8] [9]. The pathological changes of poisoning caused by Solanine are primarily acute pulmonary edema, followed by gastroenteritis and lung, liver, cardiac and renal cortical edema [10].

No significant changes have taken place to the patient in this case except the white blood cells who has undergone the preoperative liver and renal function examination, blood gas analysis and blood routine examination, and whose bleeding and clotting times were normal; nor was there significant damage on heart and lung functions. Compared with other appendicitis patients, the patient lost systemic muscle strength to the extent that he was treated with tracheal cannula and respirator-assisted respiration before operation.

It is dangerous to apply surgery treatment to a patient because little is known about changes on pharmacokinetics, physiopathology during surgery and recovery. We thought it was necessary to perform an integral assessment whether there was coagulation disorder, disturbance of water and electrolyte with the patient, and whether the heart, lung, liver and renal functions are normal before surgery, so as to decide whether the patient had indications of operation. In selecting mode of anesthesia, we choose anesthetics with insignificant effect on 
important organs as much as possible in combination with the surgery's need, and abiding by the basic requirements for anesthesia: analgesia, sedation and fast postoperative recovery. McGehee [11] once reported that, in animal experiments solanine could inhibit the activity of plasma cholinesterase and mivacurium hydrolysis and prolong the action time of mivacurium. At present, no report has been found about the effect of solanine on other muscle relaxants or anesthetics both home and abroad. Regarding the patient's imbalance of acetylcholine action like the pathophysiology course of pesticide intoxication, we didn't use drugs which may worsen the imbalance of acetylcholine action, such as atropine and muscle relaxation. The purpose was preventing these drugs from weakness of muscle and respiratory fail failure.

On the above, prior to anesthesia performed on patients against such rare diseases as potato poisoning, the anesthetist should have complete and clear understanding into the primary disease or complications, including pathophysiology, clinical manifestations, diagnosis and treatment, and assess whether patients have indications of operation. It is advisable to adopt an anesthetic mode select anesthetics without exacerbating the primary disease and complications with patients.

\section{References}

[1] Yamashoji, S. and Matsuda, T. (2013) Synergistic Cytotoxicity Induced by $\alpha$-Solanine and $\alpha$-Chaconine. Food Chemistry, 15, 669-674. http://dx.doi.org/10.1016/j.foodchem.2013.03.104

[2] Sun, H., Yang, L., Wang, Y., et al. (2014) Solanine Induces Mitochondria-Mediated Apoptosis in Human Pancreatic Cancer Cells. BioMed Research International, 2014, Article ID 805926. http://dx.doi.org/10.1155/2014/805926

[3] Lv, C., Kong, H., Dong, G., et al. (2014) Antitumor Efficacy of $\alpha$-Solanine against Pancreatic Cancer in Vitro and in Vivo. PLoS One. http://dx.doi.org/10.1371/journal.pone.0087868

[4] Mensinga, T.T., Slips, A.J. and Rompelberg, C.J. (2005) Potato Glycoalkaloids and Adverse Effects in Humans: An Ascending Dose Study. Regulatory Toxicology and Pharmacology, 41, 66-72. http://dx.doi.org/10.1016/j.yrtph.2004.09.004

[5] Patel, B., Schutte, R., Sporns, P., et al. (2002) Potato Glycoalkaloids Adversely Affect Intestinal Permeability and Aggravate Inflammatory Bowel Disease. Inflammatory Bowel Diseases, 8, 340-346. http://dx.doi.org/10.1097/00054725-200209000-00005

[6] Bodart, P. and Noirfalise, A. (2003) Glycoalkaloids in Potatoes. Revue Médicale de Liège, 58, 25-32.

[7] Clipsham, R. (2012) Brunfelsia australis (Yesterday, Today, and Tomorrow Tree) and Solanum Poisoning in a Dog. Journal of the American Animal Hospital Association, 48, 139-144. http://dx.doi.org/10.5326/JAAHA-MS-5725

[8] Xie, M.C. (2009) Study of Emergency Treatment in the Department of Internal Medicine. Shanghai Science and Technology Press, Shanghai, 564-565.

[9] Manrique-Moreno, M., Londoño-Londoño, J., Jemioła-Rzemińska, M., et al. (2014) Structural Effects of the Solanum Steroids Solasodine, Diosgenin and Solanine on Human Erythrocytes and Molecular Models of Eukaryotic Membranes. Biochimica et Biophysica Acta (BBA)—Biomembranes, 1838, 266-277. http://dx.doi.org/10.1016/j.bbamem.2013.08.003

[10] Ma, Z.F., Wang, R.R. and Song, Z.J. (2007) Emergency Medicine. Military Medical Science Press, Beijing, 503-504.

[11] McGehee, D.S., Krasoowski, M.D. and Fung, D.L. (2000) Cholinesterase Inhibition by Potato Glycoalkaloids Slows Mivacurium Metabolism. Anesthesiology, 93, 510-519. http://dx.doi.org/10.1097/00000542-200008000-00031 